\title{
$\underline{\text { A Model of Real Estate Sales as a Career Choice }}$
}

By: G. Donald Jud and Daniel T Winkler

Jud, G. D. and D. T. Winkler. "A Model of Real Estate Sales as a Career Choice," Journal of Real Estate Research, Vol. 18, No. 3, 1999, pp. 481-490.

Made available courtesy of American Real Estate Society: http://www.aresnet.org/OurJournals.htm

\section{***Note: Figures may be missing from this format of the document}

\begin{abstract}
:
This article develops a model of the probability that individuals choose careers in real estate sales. The model is estimated using Census data. Females are found to be significantly more likely than males to enter the field. For males, the probability of entering the field grows with schooling up through four years of college, and declines thereafter. For females, the probability falls with increased schooling beyond high school. Real estate sales is a career that is more appealing to both males and females with more labor market experience. For females, the probability of choosing a real estate career rises at a decreasing rate with experience. For males, the probability grows at an increasing rate. Both females and males are very responsive in their career choice decisions to changes in real earnings. The supply price elasticity, evaluated at the mean, is estimated to be +3.18 for males and +2.76 for females.
\end{abstract}

\section{Article:}

\section{Introduction}

According to the Bureau of Census, the number of real estate sales professionals totaled 743,000 in 1995, up 27\% from $1990 .{ }^{1}$ The average earnings of real estate sales persons were $\$ 25,306$. The factors that determine the earnings for real estate salespersons have been examined by Follain, Lutes and Meir (1987); Crellin, Frew and Jud (1988); Glower and Hendershott (1988); Sirmans and Swicegood (1997); and Jud and Winkler (1998), among others. These studies have reported that earnings are positively associated with hours worked, experience, education, firm size, franchise affiliation and employment in a metropolitan area. Earnings have been found to be negatively related to selling residential property, not having a broker's license and being female. ${ }^{2}$

In this article, we examine the related question of occupational choice. That is, what factors influence the probability that an individual will choose the real estate sales profession relative to others? Research on the determinants of occupational choice has investigated the choice of broad occupational categories (Boskin, 1974; Schmidt and Strauss, 1975a, b; and Orazem and Mattila, 1991). However, as far as we have been able to determine, research has not examined the factors that influence the specific occupational choice of real estate sales.

Using Census data on earnings that control for differences in gender, schooling, experience, hours worked and regional cost of living differences, we model the probability that an individual will choose to enter the real estate sales profession. The model allows us to explore the effects of schooling, experience, gender and expected earnings on occupational choice. Of particular note, 
is our finding that the choice of a real estate sales career is very elastic with respect to earnings. This finding has important implications for brokers, regulators and others interested in the future of the brokerage industry. This article provides a review of the occupational choice literature, lays out the occupational probability model, presents and discusses the empirical data and results, and concludes with a summary of findings and avenues for further research.

\section{Literature Review}

Boskin (1974) explores occupational choice using a logit model stratified by age, sex and occupational group. His model explains occupational choice with variables related to: (1) the present value of potential lifetime earnings; (2) relative training costs; and (3) expected earnings loss due to unemployment. Boskin's empirical results were consistent with the human capital hypothesis that workers choose occupations to maximize the present value of potential lifetime earnings.

Schmidt and Strauss (1975a) employ five board occupational titles (professional, white collar, craft, blue collar and menial) based on census titles. They relate the choice of these occupational categories to education, experience, race and gender. Their results, using logit analysis, indicate that gender and race strongly influence the type of job individuals select. Schmidt and Strauss (1975b) utilize a simultaneous logit model where the choice of occupation and industry are jointly determined.

More recently, Orazem and Mattila (1991) study the proportion of male high school graduates who take jobs in six broad occupational categories. Their data is drawn from twenty-three school districts in Maryland from 1951 through 1969 and follows two academic groups:

vocation/technical school graduates and graduates of four-year colleges and universities. Using a multinomial logit specification, they find that average career earnings and the distribution of earnings per unit of human capital influence career choice. School quality also is found to affect occupational choice.

\section{Occupational Probability Model}

The occupational probability model developed by Schmidt and Strauss (1975a, b) provides the basis for the formation of our model. The general form of the empirical model used in this study is as follows: ${ }^{3}$

$$
P_{l, J}=f\left(F_{l, J}, S_{l, J}, R E_{l, J}, \varepsilon_{l}\right),
$$

where:

$P_{I, J}=$ The proportion of individuals in the Ith age/sex/schooling category of the $J$ th MSA who are real estate sales professionals;

$F_{l, J}=$ A dummy variable equal to 1 if the category is female ( 0 otherwise);

$E_{I, J}=$ The average number of years of general labor market experience in the $I$ th category;

$S_{I, J}=$ The average number of years of formal schooling in the Ith category;

$R E_{l, J}=$ The average real earnings of real estate sales professionals in the Ith category (in $\$ 1,000$ s); and

$\varepsilon_{l}=$ A stochastic term. 
The estimated coefficient on the schooling variable can be partitioned into different levels of schooling using a spline function as follows (Greene, 1997:389):

$$
P_{l, J}=\alpha+\beta_{1}+\beta_{2} S_{I, J}+\delta_{1} d_{1}\left(S_{I, J}-12\right)+\delta_{2} d_{2}\left(S_{I, J}-16\right),
$$

where:

$d_{1}=1$ if $S_{I, J} \geq$ twelve years ( 0 otherwise); and

$d_{2}=1$ if $S_{I, J} \geq$ sixteen years ( 0 otherwise).

The spline function permits the effect of schooling on the proportion of individuals choosing the real estate profession to differ for various levels of schooling such as primary, secondary, undergraduate and graduate school.

General labor market experience is captured using the traditional human-capital approach as follows:

$$
\text { Experience }(E)=\text { Age }- \text { Schooling }(S)-5 \text {. }
$$

To examine the possibility of a nonlinear relationship, we introduce both experience $(\mathrm{E})$ and experience squared $\left(\mathrm{E}^{2}\right)$ into the probability equation.

The use of proportions data as the dependent variable creates some problems when using a regression approach (Greene, 1997). One complication is heterskedasticity between the error term $\left(\varepsilon_{1}\right)$ and the independent variables. A second more serious problem is that the predictions from the model given by $\beta^{\prime} \mathrm{x}$ (where $\beta^{\prime}$ is the vector of estimated regression coefficients and $\mathrm{x}$ is the vector of independent variables) cannot be constrained to a zero-one interval. Greene (1997:874) indicates this produces nonsensical probabilities and negative variances.

Boskin (1974) and Schmidt and Strauss (1975a, b) address the shortcomings of the regression approach through the use of a logistical probability (or logit) model. ${ }^{4}$ This model addresses the aforementioned statistical problems associated with using regression analysis with proportion data.

Data

The data for this research are obtained from the Bureau of the Census, Census of Population and Housing 1990 (1994). ${ }^{5}$

Exhibit 1 presents the descriptive statistics for full-time real estate sales professionals with the total sample in Panel A and gender-based sub-samples in Panels B and C. The total sample includes 3,079 observations from $61 \mathrm{MSAs}$; these observations are the proportions of individuals in real estate with the associated personal characteristics of gender, schooling, experience and average earnings.

The nominal earnings figures taken from the Census report are deflated by the American Chambers of Commerce Research Association (ACCRA, 1989) regional 
Exhibit 1

Descriptive Statistics

\begin{tabular}{|c|c|c|c|c|}
\hline Variable & Mean & Std. Dev. & Min. & Max. \\
\hline \multicolumn{5}{|c|}{ Panel A: Descriptive Statistics for Full Sample } \\
\hline Proportion, $P_{l}$ & 0.013 & 0.020 & 0.000 & 0.379 \\
\hline Female, $F_{i}$ & 0.485 & 0.500 & 0.000 & 1.000 \\
\hline Experience, $E_{i}$ & 25.363 & 14.870 & 0.000 & 55.000 \\
\hline Experience Squared, $E_{1}^{2}$ & 864.319 & 811.476 & 441.000 & $3,025.000$ \\
\hline Schooling, $S_{\text {, }}$ & 14.065 & 2.548 & 8.000 & 18.000 \\
\hline College, $d_{1}\left(S_{1}-12\right)$ & 2.338 & 2.146 & 0.000 & 6.000 \\
\hline Grad. Sch., $d_{2}\left(S_{1}-16\right)$ & 0.291 & 0.705 & 0.000 & 2.000 \\
\hline Real Earnings, RE, & 32.930 & 26.293 & 0.311 & 721.332 \\
\hline \multicolumn{5}{|c|}{ Panel B: Descriptive Statistics for Male Sample } \\
\hline Proportion, $P_{i}$ & 0.012 & 0.017 & 0.000 & 0.379 \\
\hline Experience, $E_{1}$ & 25.823 & 15.105 & 0.000 & 55.000 \\
\hline Experience Squared, $E_{l}^{2}$ & 894.862 & 832.868 & 0.000 & $3,025.000$ \\
\hline Schooling, $S_{\text {, }}$ & 14.164 & 2.631 & 8.000 & 18.000 \\
\hline College, $d_{1}\left(S_{1}-12\right)$ & 2.458 & 2.178 & 0.000 & 6.000 \\
\hline Grad. Sch., $d_{2}\left(S_{1}-16\right)$ & 0.325 & 0.738 & 0.000 & 2.000 \\
\hline Real Earnings, $R E_{l}$ & 39.490 & 31.648 & 0.311 & 721.332 \\
\hline \multicolumn{5}{|c|}{ Panel C: Descriptive Statistics for Female Sample } \\
\hline Proportion, $P_{l}$ & 0.015 & 0.021 & 0.000 & 0.291 \\
\hline Experience, $E_{l}$ & 24.873 & 14.605 & 0.000 & 55.000 \\
\hline Experience Squared, $E_{l}^{2}$ & 831.831 & 787.063 & 0.000 & $3,025.000$ \\
\hline Schooling, $S_{l}$ & 13.961 & 2.455 & 8.000 & 18.000 \\
\hline College, $d_{1}\left(S_{l}-12\right)$ & 2.211 & 2.106 & 0.000 & 6.000 \\
\hline Grad. Sch., $d_{2}\left(S_{1}-16\right)$ & 0.255 & 0.667 & 0.000 & 2.000 \\
\hline Real Earnings, $R E_{1}$ & 25.952 & 16.347 & 1.526 & 260.708 \\
\hline
\end{tabular}

Note: Panel A: $N=3,079$; Panel B: $N=1,587$; and Panel C: $N=1,492$.

cost of living index to adjust for regional differences in the cost of living. The ACCRA index measures the relative cost of consumer goods and services in MSAs across the country.

Real estate sales professionals comprise on average about $1.33 \%$ of the total workforce in the 61 MSAs in our sample. Approximately $48.5 \%$ or real estate sales professionals are female. The average real earnings of all sales professionals are $\$ 32,930$. Males earn $\$ 39,490$, while females earn $\$ 25,952$, or about $66 \%$ of their male counterparts. Males, however, have slightly more experience and education. ${ }^{6}$ 


\section{Empirical Results}

Exhibit 2 presents the findings for the OLS regression and logit models. The OLS regression shows a statistically significant adjusted $\mathrm{R}^{2}$ of $34 \%$. The error term, however, in the OLS model is heteroskedastic with respect to the independent variables, and the independent variable coefficients have suspect values. Predictions from the OLS model are not constrained to the 0-1 interval (Greene, 1997:875). ${ }^{7}$

\begin{tabular}{|c|c|c|c|}
\hline \multicolumn{4}{|c|}{$\begin{array}{l}\text { Exhibit } 2 \\
\text { Logit Model Results for Full Sample: } \\
\text { Real Estate Profession versus Other Occupations }\end{array}$} \\
\hline Variable & $\begin{array}{l}\text { OLS } \\
\text { Regression } \\
\text { Coefficient }^{\mathrm{a}}\end{array}$ & $\begin{array}{l}\text { Logit } \\
\text { Coefficient }\end{array}$ & $\begin{array}{l}\text { Logit } \\
\text { Slope } \\
\text { Coefficient }^{a}\end{array}$ \\
\hline Constant & $\begin{array}{l}-1.941 \\
-4.077\end{array}$ & $\begin{array}{r}-9.847 \\
-123.453\end{array}$ & $\begin{array}{r}-6.856 \\
-126.221\end{array}$ \\
\hline Female, $F_{i}$ & $\begin{array}{l}0.337 \\
5.660\end{array}$ & $\begin{array}{r}0.270 \\
55.191\end{array}$ & $\begin{array}{r}0.188 \\
55.556\end{array}$ \\
\hline Experience, $E_{l}$ & $\begin{array}{l}-0.029 \\
-3.803\end{array}$ & $\begin{array}{r}0.029 \\
36.701\end{array}$ & $\begin{array}{r}0.020 \\
36.913\end{array}$ \\
\hline Experience Squared, $E_{l}^{2}$ & $\begin{array}{r}0.002 \\
12.649\end{array}$ & $\begin{array}{r}0.001 \\
13.982\end{array}$ & $\begin{array}{r}0.001 \\
13.964\end{array}$ \\
\hline Schooling, $S_{l}$ & $\begin{array}{l}0.137 \\
3.364\end{array}$ & $\begin{array}{r}0.290 \\
43.164\end{array}$ & $\begin{array}{r}0.202 \\
43.667\end{array}$ \\
\hline College, $d_{1}\left(S_{l}-12\right)$ & $\begin{array}{l}0.277 \\
5.312\end{array}$ & $\begin{array}{l}0.040 \\
5.479\end{array}$ & $\begin{array}{l}0.028 \\
5.473\end{array}$ \\
\hline Grad. Sch., $d_{2}\left(S_{1}-16\right)$ & $\begin{array}{r}-0.771 \\
-13.115\end{array}$ & $\begin{array}{r}-0.637 \\
-130.357\end{array}$ & $\begin{array}{r}-0.444 \\
-132.795\end{array}$ \\
\hline Real Earnings, $R E_{l}$ & $\begin{array}{l}-0.001 \\
-1.030\end{array}$ & $\begin{array}{r}0.002 \\
14.530\end{array}$ & $\begin{array}{c}0.001 \\
14.53\end{array}$ \\
\hline
\end{tabular}

The logit results are shown in the second and third columns of Exhibit 2. The log- likelihood in column 2 indicates a statistically significant model. All coefficients are statistically significant at the 0.01 level; t-ratios are shown below the coefficients.

The coefficient estimates obtained from the logit model, reported in Exhibit 2, are not interpretable as changes in the dependent variable per unit change of the independent variable. For that, the marginal effects (logit slope coefficients) must be computed by taking the derivative of the logit equation with respect to each independent variable, evaluated at the mean. These results are shown in the third column of Exhibit $2 .^{8}$

All logit slopes (marginal effects) reported in Exhibit 2 are statistically significant at the 0.01 level. Interpreting the logit slope, the probability that an individual will be in the real estate sales profession (relative to other occupations in the workforce) is $0.19 \%$ larger for females than for males, holding constant experience, education and earnings. 
General labor market experience (E) has a positive influence on the choice of a real estate sales career. Individuals with more work experience have a higher probability of entering real estate sales than those with less experience. In addition, because the squared experience term is positive, the effect of experience rises at an increasing rate. For example, an individual with five years of labor market experience is $0.10 \%$ more likely to be in real estate sales than a new labor market entrant.

The influence of elementary and secondary schooling as measured by the logit schooling slope coefficient (S) indicates a $0.20 \%$ increase in the probability per year of elementary and secondary schooling. For example, a high school graduate with twelve years of schooling is $0.80 \%$ more likely to be in real estate sales than an individual with only eight years of schooling. (Note that the minimum level of schooling in our sample was eight years.)

For individuals completing some college, the probability increases an additional $0.03 \%$ per year of college completed. Therefore, an individual with four years of college is $0.92 \%$ more likely to be in real estate sales than an individual with only a high school degree.

Schooling beyond college reduces the probability that an individual will be in real estate sales. The marginal probability falls $-0.44 \%$ for every year of schooling beyond four years of college. For example, an individual with two years of graduate training is $0.43 \%$ less likely to be in real estate sales than an individual with only four years of college.

Higher real earnings increase the probability that an individual will choose a career in real estate sales. It is estimated that a one-thousand-dollar increase in real earnings raises the probability of being in real estate sales by $0.0013 \%$ per thousand dollars. (Note that OLS regression finds a non-statistically significant real earnings coefficient.) The supply price elasticity of being in real estate sales can be calculated as the percentage change in the probability divided by the percentage change in earnings [that is, $\left(\%\right.$ chg. $\left.\mathrm{P}_{\mathrm{I}, \mathrm{J}}\right) /\left(\% \mathrm{chg}\right.$. $\left.\mathrm{RE}_{\mathrm{I}, \mathrm{J}}\right)$ ]. Evaluating this elasticity at the mean of the full sample yields an elasticity coefficient of $+3.07 \%$, which indicates that the occupational choice decisions of individuals choosing a career in real estate sales are highly responsive to changes in earnings.

While Exhibit 2 provides interesting insights, the statistical significance of the female dummy variable (F) in Exhibit 2 indicates that the female and male subsamples may have substantially different logit and slope coefficients. Exhibit 3 reports the logit and slope (marginal effects) coefficients by gender. The results suggest the two subsamples do indeed respond to the independent variables in substantially different ways. With the exception of the experience variable for the male subsample, all logit and slope coefficients are statistically significant at the 0.01 level.

General labor market experience increases the probability of females choosing the real estate profession by $0.05 \%$ per year; however, because the squared term is negative, the probability increases at a decreasing rate. For males, the coefficient on the experience term $(\mathrm{E})$ is negative but not statistically significant at the 0.05 level. However, the coefficient on the experiencesquared term is a positive and significant 0.00045 . Thus, a male with five years of experience has 
about a $0.01 \%$ higher probability of being in real estate sales than an individual with no experience, and the probability rises with experience at an increasing rate.

\section{Exhibit 3}

Logit Model Results by Gender: Real Estate Profession versus Other Occupations

\begin{tabular}{|c|c|c|c|c|}
\hline & \multicolumn{2}{|c|}{ Male Sample } & \multicolumn{2}{|c|}{ Female Sample } \\
\hline & $\begin{array}{l}\text { Logit } \\
\text { Coefficient }\end{array}$ & $\begin{array}{l}\text { Slope } \\
\text { Coefficient }^{a}\end{array}$ & $\begin{array}{l}\text { Logit } \\
\text { Coefficient }\end{array}$ & $\begin{array}{l}\text { Slope } \\
\text { Coefficient }^{\mathrm{a}}\end{array}$ \\
\hline Constant & $\begin{array}{r}-8.958 \\
-89.091\end{array}$ & $\begin{array}{r}-5.739 \\
-90.813\end{array}$ & $\begin{array}{l}-10.585 \\
-81.142\end{array}$ & $\begin{array}{r}-8.070 \\
-82.364\end{array}$ \\
\hline Experience, $E_{l}$ & $\begin{array}{l}-0.002 \\
-1.690\end{array}$ & $\begin{array}{l}-0.001 \\
-1.689\end{array}$ & $\begin{array}{r}0.062 \\
50.486\end{array}$ & $\begin{array}{r}0.048 \\
51.793\end{array}$ \\
\hline Experience Squared, $E_{l}^{2}$ & $\begin{array}{r}0.001 \\
35.290\end{array}$ & $\begin{array}{r}0.001 \\
35.286\end{array}$ & $\begin{array}{r}-0.001 \\
-14.300\end{array}$ & $\begin{array}{r}-0.001 \\
-14.375\end{array}$ \\
\hline Schooling, $S_{l}$ & $\begin{array}{r}0.235 \\
27.691\end{array}$ & $\begin{array}{r}0.151 \\
27.979\end{array}$ & $\begin{array}{r}0.350 \\
31.983\end{array}$ & $\begin{array}{r}0.267 \\
32.272\end{array}$ \\
\hline College, $d_{1}\left(S_{1}-12\right)$ & $\begin{array}{r}0.156 \\
16.653\end{array}$ & $\begin{array}{r}0.100 \\
16.592\end{array}$ & $\begin{array}{l}-0.083 \\
-7.132\end{array}$ & $\begin{array}{l}-0.064 \\
-7.141\end{array}$ \\
\hline Grad. Sch., $d_{2}\left(S_{1}-16\right)$ & $\begin{array}{r}-0.710 \\
-118.932\end{array}$ & $\begin{array}{r}-0.455 \\
-121.903\end{array}$ & $\begin{array}{r}-0.573 \\
-65.154\end{array}$ & $\begin{array}{r}-0.437 \\
-65.947\end{array}$ \\
\hline Real Earnings, $R E_{l}$ & $\begin{array}{r}0.002 \\
11.157\end{array}$ & $\begin{array}{r}0.001 \\
11.155\end{array}$ & $\begin{array}{l}0.002 \\
6.851\end{array}$ & $\begin{array}{l}0.002 \\
6.852\end{array}$ \\
\hline
\end{tabular}

aSlope coefficients have been multiplied by $10 \mathrm{E}+2$ to reduce the number of leading zeros. The log-likelihood for the male sample is -633105 . The log-likelihood for the female sample is -474875 .

Each year of primary and secondary schooling increases the probability by $0.27 \%$ for females and only $0.15 \%$ for males. Interestingly, with college education, the probability drops to $0.20 \%$ per year for females and increases to $0.25 \%$ for males. Graduate school appears to reduce the probability by roughly similar magnitudes for both males and females.

The real earnings coefficients for both males and females are positive and statistically significant. The supply price elasticity, evaluated at the mean of each sample, is +3.18 for males and +2.76 for females.

\section{Summary and Conclusions}

These findings have important implications for the real estate profession. Females are significantly more likely than males to enter the field. In reference to schooling, while individuals who are in the field of real estate may regard themselves as professionals, individuals with advanced degrees are not as likely to choose a real estate sales career. For males, the probability of entering the field grows with schooling up through four years of college, and declines thereafter. For females, the probability falls with increased schooling beyond high school.

Real estate sales is a career that is more appealing to both males and females with more labor market experience. For females, the probability of choosing a real estate career rises at a decreasing rate with experience. For males, the probability grows at an increasing rate. 
Both females and males are very responsive in their career choice decisions to differences in real earnings. The supply price elasticity, evaluated at the mean, is estimated to be +3.18 for males and +2.76 for females.

Our study has enabled us to estimate how schooling, experience and earnings influence real estate sales as a career choice. Because of the limitations of the Census data, we have not been able to explore how decisions to enter and leave the real estate field are influenced by such factors as marital status, household size, race and other factors. We believe this remains an area that merits additional research.

\section{Endnotes}

1. Bureau of the Census, Statistical Abstract of the United States, 1998 (Table 793).

2. See Benjamin, Jud and Sirmans (forthcoming).

3. A variable for race was not available due to limitations of the Census data. When sample sizes are too small, the Bureau of Census does not provide detailed data for subgroups.

4. This model is a transformation of the regression approach as follows (Greene, 1997:895):

$$
\begin{aligned}
& P_{i}=F\left(\beta^{\prime} \mathbf{x}_{i}\right)+\varepsilon_{i} \text { and } \\
& F^{-1}\left(P_{i}\right)=z_{i}=\beta^{\prime} \mathbf{x}_{i}+\mu
\end{aligned}
$$

with

$$
E\left[\mu_{i}\right]=0 \text { and } \operatorname{Var}\left[\mu_{i}\right]=\frac{F_{i}(1-F)}{n i f_{i}^{2}}
$$

Where $\mathrm{n}$, is the number of individuals who are real estate professionals. Weighted least squares is performed to produce the minimum chi-squared estimates of $\beta$ using the following weights:

$$
w_{i}=\left[n_{i} \Lambda_{i}\left(1-\Lambda_{i}\right)\right]^{1 / 2},
$$

With $\Lambda$ indicating the logistic distribution function.

The inverse for the logistic model is obtained as follows:

$$
\pi_{i}=\frac{\exp \left(\beta^{\prime} \mathbf{x}_{i}\right)}{1+\exp \left(\beta^{\prime} x_{i}\right)}
$$

and

$$
\ln \left(\frac{\pi_{i}}{1-\pi_{i}}\right)=\beta^{\prime} \mathbf{x}_{i}
$$

5. The data contains survey information from 1989. More recent census data will not be available until presumably 2004.

6. For an analysis of the earnings of real estate professionals, see Jud and Winkler (1998).

7. We also examined a fixed-effects and random effects model using MSA as the classification variable. The fixed-effects model provided minimal changes in the coefficient values and adjusted $\mathrm{R}^{2}$ in comparison to the specification reported in Exhibit 2 (without fixed effects). A 
Hausman test comparing the fixed- and random-effects model specifications rejects the fixedeffects model in favor of the random effects model $(\mathrm{H}=7.57)$. However, given the problems of linear regression using proportions data, none of these regressions is appropriate.

8. Because the marginal effects are estimated using a cross-sectional model, the standard precautions should be applied when using these estimates in any forecasts.

\section{References}

ACCRA, Cost of Living Index, Second Quarter, 1989.

Benjamin, J. D., G. D. Jud and G. S. Sirmans, What Do We Know About Real Estate Brokerage?

Journal of Real Estate Research, 2000, 20:1/2.

Boskin, M. P., A Conditional Logit Model of Occupational Choice, Journal of Political Economy, 1974, 82:2, 389-98.

Bureau of the Census, Census of Population and Housing (1990): Subject Summary Tape File (SSTF) 22, Earnings by Occupation and Education, 1994.

Crellin, G. E., J. R. Frew and G. D. Jud, The Earnings of REALTORS: Some Empirical

Evidence, Journal of Real Estate Research, 1988, 3, 69-78.

Follain, J. R., T. Lutes and D. A. Meier, Why Do Some Real Estate Salespeople Earn More Than Others?, Journal of Real Estate Research, 1987, 2, 73-81.

Glower, M. and P. H. Hendershott, The Determinants of REALTOR Income, Journal of Real Estate Research, 1988, 3, 53-68.

Greene, W. H., Econometric Analysis, third edition, New York: Macmillan Publishing Company, 1997.

Jud, G. D. and D. T. Winkler, The Earnings of Real Estate Salespersons and Others in the Financial Services Industry, Journal of Real Estate Finance and Economics, 1998, 17:3, 27991. Orazem, P. F. and J. P. Mattila, Human Capital, Uncertain Wage Distributions, and Occupational and Educational Choices, International Economic Review, 1991, 32:1, 103-22.

Schmidt, P. and R. P. Strauss, The Predication of Occupation Using Multiple Logit Models, International Economic Review, 1975, 16:2, 471-86.

, Estimation of Models with Jointly Dependent Qualitative Variables: A Simultaneous

Logit Approach, Econometrica, 1975, 43:4, 745-55.

G. S. Sirmans and P. Swicegood, Determinants of Real Estate Licensee Income, Journal of Real Estate Research, 1997, 14:1/2, 137-59. 